\title{
BMJ
}

\section{Home versus outpatient ultraviolet B phototherapy for mild to severe psoriasis: pragmatic multicentre randomised controlled non-inferiority trial (PLUTO study)}

\author{
Mayke B G Koek, research fellow, Erik Buskens, professor of medical technology assessment, ${ }^{2,3}$ Huib van \\ Weelden, investigator photodermatology, ${ }^{1}$ Paul H A Steegmans, dermatologist, ${ }^{4}$ Carla A F M Bruijnzeel- \\ Koomen, professor of dermatology/allergology, ${ }^{1}$ Vigfús Sigurdsson, dermatologist ${ }^{1}$
}

${ }^{1}$ Department of Dermatology/ Allergology, University Medical Center Utrecht, Heidelberglaan 100, 3584 CX Utrecht, Netherlands

${ }^{2}$ Department of Epidemiology, University Medical Center Groningen, University of Groningen, Groningen,

Netherlands

${ }_{3}^{3}$ Julius Center for Health Sciences and Primary Care, University Medical Center Utrecht, Utrecht, Netherlands

${ }^{4}$ Department of Dermatology, St Antonius Hospital, Nieuwegein, Netherlands

Correspondence to: M B G Koek author@koek.com

Cite this as: BMJ 2009;338:b1542 doi:10.1136/bmj.b1542

\section{ABSTRACT}

Objective To determine whether ultraviolet $B$ phototherapy at home is equally safe and equally effective as ultraviolet B phototherapy in an outpatient setting for patients with psoriasis.

Design Pragmatic multicentre single blind randomised clinical trial (PLUTO study).

Setting Dermatology departments of 14 hospitals in the Netherlands.

Participants 196 patients with psoriasis who were clinically eligible for narrowband (TL-01) ultraviolet B phototherapy. The first 105 consecutive patients were also followed for one year after therapy.

Intervention Ultraviolet B phototherapy at home using a TL-01 home phototherapy unit compared with standard narrowband ultraviolet $B$ phototherapy in an outpatient setting. Both therapies were done in a setting reflecting routine daily practice in the Netherlands.

Main outcome measures The main outcome measure was effectiveness as measured by the proportion of patients with a $50 \%$ or more reduction of the baseline psoriasis area and severity index (PASI) or self administered psoriasis area and severity index (SAPASI), called the PASI 50 and SAPASI 50 (relevant treatment effect). Another outcome of effectiveness was the percentage reduction in median scores on the PASI as well as SAPASI. Also the proportions of patients reaching the PASI 75 and SAPASI 75 (successful treatment effect), and the PASI 90 and SAPASI 90 (almost complete clearance) were calculated. Other secondary outcomes were quality of life (SF-36, psoriasis disability index), burden of treatment (questionnaire), patients' preferences and satisfaction (questionnaire), and dosimetry and short term side effects (diary).

Results $82 \%$ of the patients treated at home compared with $79 \%$ of the patients treated in an outpatient setting reached the SAPASI 50 (difference $2.8 \%, 95 \%$ confidence interval $-8.6 \%$ to $14.2 \%$ ), and $70 \%$ compared with $73 \%$ reached the PASI $50(-2.3 \%,-15.7 \%$ to $11.1 \%)$. For patients treated at home the median SAPASI score decreased $82 \%$ (from 6.7 to 1.2 ) and the median PASI score decreased $74 \%$ (from 8.4 to 2.2 ), compared with
$79 \%$ (from 7.0 to 1.4 ) and $70 \%$ (from 7.0 to 2.1 ) for patients treated in an outpatient setting. Treatment effect as defined by the mean decline in PASI and SAPASI scores was significant $(P<0.001)$ and similar across groups (P>0.3). Total cumulative doses of ultraviolet $B$ light were similar (51.5 v $46.1 \mathrm{~J} / \mathrm{cm}^{2}$, difference $5.4,95 \%$ confidence interval -5.2 to 16.0 ), and the occurrence of short term side effects did not differ. The burden of undergoing ultraviolet B phototherapy was significantly lower for patients treated at home (differences 1.23 to 3.01, all $P \leq 0.001)$. Quality of life increased equally regardless of treatment, but patients treated at home more often rated their experience with the therapy as "excellent" ( $42 \%$, 38/90) compared with patients treated in the outpatient department (23\%, 20/88; $\mathrm{P}=0.001)$.

Conclusion Ultraviolet B phototherapy administered at home is equally safe and equally effective, both clinically and for quality of life, as ultraviolet B phototherapy administered in an outpatient setting. Furthermore, ultraviolet $B$ phototherapy at home resulted in a lower burden of treatment and led to greater patients' satisfaction.

Trial registration Current Controlled Trials ISRCTN83025173 and Clinicaltrials.gov NCT00150930.

\section{INTRODUCTION}

Psoriasis is a chronic skin disorder which, regardless of extent, can affect patients' quality of life. The disease can be treated symptomatically in several ways. An effective treatment that is often applied is phototherapy using ultraviolet B light. ${ }^{1-4}$ Ultraviolet B phototherapy is indicated when topical treatment is insufficient. It is generally offered in an outpatient clinic, which requires patients to travel two or three times a week for treatment. This makes it a relatively time consuming treatment both for patients and for hospital staff, imposing a substantial burden on patients and society.

To overcome the drawbacks of ultraviolet B phototherapy in the outpatient clinic, equipment for use at home was introduced in the late $1970 \mathrm{~s} .{ }^{5-8}$ Although ultraviolet B phototherapy has been used at home ever since, ${ }^{7-14}$ its safety and effectiveness and compliance 
with treatment have been debated. Non-evidence based fears are often expressed about higher attendant risks such as inaccurate dosimetry, phototoxicity, suboptimal treatment, and unsupervised continuation of irradiations after treatment has finished. ${ }^{11-24}$ It is thought that these risks influence the occurrence of acute side effects and lead to an increased cumulative dose and hence promote photocarcinogenesis and photoageing.

We have shown that over $55 \%$ of dermatologists consider ultraviolet B phototherapy at home to be inferior to such therapy in the outpatient department. Moreover, about 30\% think that ultraviolet B phototherapy at home carries higher risks than when used in hospital, risks such as erythema, burns, carcinogenesis, and photoageing. ${ }^{25}$ Research using randomised designs is non-existent, and literature on the subject remains scarce - that is, firm evidence supporting or discouraging the use of ultraviolet $\mathrm{B}$ phototherapy at home is simply lacking. ${ }^{25}$

Although many dermatologists hardly ever prescribe ultraviolet $B$ phototherapy at home, in some settings such treatment is common. We reported that 3000 panels for dispensing ultraviolet B light had been sold in Germany and 5000 in the United States and that two Dutch home care institutions (independent suppliers of medical equipment, inclusive of support from specialist nurses) were successfully providing ultraviolet B light equipment and supervision for 1400 patients with psoriasis annually. We also showed that in the Netherlands about $5 \%$ of patients treated with ultraviolet B light are prescribed phototherapy at home. Some dermatologists even reported prescribing home therapy to all their patients treated with ultaviolet B light. ${ }^{25}$

To summarise, firm evidence on which to base a considered policy decision about ultraviolet B phototherapy at home is lacking. ${ }^{25}$ In the absence of sound evidence based on randomised research, discussions on home ultraviolet B phototherapy will continue to result in the spread of non-evidence based opinions and opinion based medicine. ${ }^{25}$ Notably, little attention has been paid to the possible positive effects of home therapy on quality of life, patients' satisfaction, and the burden of treatment.

On the basis of recent experience with ultraviolet $B$ phototherapy at home and data from a 1993 pilot we expected home treatment to be as equally effective as current ultraviolet $B$ phototherapy used in outpatient settings. ${ }^{9}$ We aimed to establish that treatment effect, safety, quality of life, and cost effectiveness of home phototherapy do not differ substantially from that of conventional ultraviolet B phototherapy in an outpatient clinic. Additionally, with home treatment we expected a lower burden from treatment and higher patients' satisfaction. We compared both treatments in a setting reflecting routine daily practice in the Netherlands and focused on narrowband (TL-01) ultraviolet B phototherapy for psoriasis. ${ }^{26}$ The Dutch acronym for this trial was PLUTO. The cost effectiveness data will be published separately.

\section{METHODS}

From 2002 to 2005 we carried out a pragmatic multicentre single blinded randomised trial comparing ultraviolet B phototherapy at home with ultraviolet $B$ phototherapy in an outpatient setting. ${ }^{26}$ The participants and methods are described in detail elsewhere (www.biomedcentral.com/content/pdf/1471-2288-639.pdf). ${ }^{26}$

A pragmatic design is a recognised methodology for tackling questions on effectiveness in daily practice as opposed to efficacy in a "controlled" setting..$^{27-29}$ Thus in our trial the interventions were administered as they would be routinely, with the management of the intervention left to the discretion of the prescribing clinician - that is, dermatologists were encouraged to carry out the assigned treatment as they would normally. Consequently, part of the comparison is possible variability in actual frequency of irradiations, dosage, compliance, support, and equipment used. We did not control for these and other possible differences related to treatment because they will occur in a real life situation. Besides the treatment, the selection of patients also reflected routine practice. Blinding participants to treatment was not possible, and because of the pragmatic design of the study it was undesirable to blind the dermatologists. The extent and severity of the psoriasis was, however, assessed by an independent research nurse blinded to the treatment arm. ${ }^{26}$

Since patient selection should reflect routine clinical practice ${ }^{28-30}$ we invited patients with plaque or guttate psoriasis to participate if they were considered clinically eligible for TL-01 ultraviolet B phototherapy. As a result the severity of psoriasis was not a selection criterion. Ultraviolet B treatment had to be prescribed by the patient's own dermatologist, and patients provided written informed consent to undergo treatment according to randomisation. We excluded patients younger than 18 years, those who might not comply with treatment, those with contraindications, and for practical reasons. Further details are described elsewhere. ${ }^{26}$ The main selection criterion of being clinically eligible for TL-01 ultraviolet B phototherapy was purely pragmatic and was left to the discretion of the patients' own dermatologists. The dermatologists were, however, explicitly discouraged from increasing their prescriptions because of the study.

\section{Sample size}

On the basis of recent experience with home ultraviolet B phototherapy and data from a 1993 pilot we expected the treatments to be equally effective. ${ }^{9}$ The sample size was therefore calculated in accordance with a negative trial approach. ${ }^{31}$ We considered a $50 \%$ or more improvement in the severity of psoriasis from baseline to be a relevant clinical response. From the literature we expected about $85 \%$ of the patients treated with ultraviolet B light to show at least a $50 \%$ improvement of their psoriasis. ${ }^{32}$ We determined that with an $\alpha$ of 0.05 , $\beta$ of 0.20 (power $80 \%$ ), and a distinguishable decline $(\Delta)$ in proportion of patients of $-15 \%$ (from $85 \%$ to $70 \%$ ) we would need 90 patients per 
treatment group. ${ }^{26}$ To allow for missing data and losses to follow-up we aimed to recruit 100 patients per group, 200 in total. From the end of the treatment onwards we considered a consecutive sample of 100 patients ( 50 per group) to be sufficient to obtain accurate estimates of cumulative costs. ${ }^{26}$

\section{Randomisation procedure}

After baseline data had been collected, a randomisation number corresponding to ultraviolet $B$ phototherapy either at home or in an outpatient department was drawn from a computer generated list. Randomisation was done using stratified randomisation, in particular the minimisation method. ${ }^{2633}$ This method takes into account the recruiting hospital and possible previous experiences with ultraviolet phototherapy. After randomisation both the patient and the dermatologist were informed of the assigned treatment, and this treatment was started according to standard practice.

\section{Therapy}

Patients randomised to outpatient treatment received TL-01 ultraviolet B phototherapy in their local hospital. The hospitals used their own treatment schedules and their own (full circle) units. Some types of units had ultraviolet light indicators measuring the intensity of irradiation $\left(\mathrm{mW} / \mathrm{cm}^{2}\right)$; others did not and measured only treatment time. Accordingly, treatments were prescribed either in dose $\left(\mathrm{J} / \mathrm{cm}^{2}\right)$ or in units of time (seconds). ${ }^{26}$ Determination of the minimal erythema dose before treatment was only done if that was routine practice for the hospital. Patients were treated two or three times a week, depending on the hospital.

Patients randomised to receive home ultraviolet $\mathrm{B}$ phototherapy were temporarily provided with a TL01 home phototherapy unit (Waldmann UV 100; Waldmann, Villingen-Schwenningen, Germany). This device comprises a semicircular arrangement of lamps without an intensity indicator. Therefore treatments were prescribed in units of time (seconds). The equipment was rented out by the home care institutions, which also delivered the unit to the patients' home and collected it at the end of the treatment period. On delivery, a nurse from the home care institution provided 30-60 minutes' training in use of the unit. Patients signed a contract restricting use of the unit to themselves. Finally, the patients received a treatment schedule, set in time (seconds). No minimal erythema dose was tested. Irradiation took place three or four times a week (every other day), sometimes starting with daily irradiations. The choice of subsequent steps in the treatment schedule depended on the extent of side effects experienced (erythema or burning sensation). Patients could contact the nursing staff of the home care institution for supervision. The cost for the nurses' services, delivery, and collection of the unit was included in the rental price. ${ }^{26}$

Summarising, the irradiation schedules for both treatment groups were those normally used by the hospitals and home care institutions. Neither equipment nor schedules were modified for the trial. We observed standard practice and therefore did not impose a prespecified treatment regimen on the participants, and as with daily practice we allowed adjuvant use of topical therapy to continue throughout ultraviolet B treatment. No other additional treatments or changes to the original treatment plan were intended. However, to compare the two treatments under practical conditions and to reflect clinical reality, alterations to the initial treatment plan were allowed if the dermatologists decided they were necessary. As such, all changes to treatment originating after inclusion and randomisation were permitted and were no reason for exclusion. ${ }^{26}$

\section{Outcome measures}

We determined the severity of disease by using the psoriasis area and severity index (PASI) ${ }^{34}$ and the self administered psoriasis area and severity index (SAPASI) ${ }^{35-37}$ Both scales range from 0 (no lesions) to 72 (extensive erythroderma of the severest degree). The main outcome measure was effectiveness, as measured by the proportion of patients with a $50 \%$ or more improvement of the baseline PASI or SAPASI (called, respectively, PASI 50 and SAPASI 50), which is considered a relevant treatment effect. Another outcome measure was the percentage reduction in median PASI and SAPASI scores. Also, the PASI 75 and SAPASI 75 (proportion of patients reaching a 75\% improvement of the PASI and SAPASI, a so called successful treatment effect), the PASI 90 and SAPASI 90 (almost complete clearance), and a patient assessed visual severity assessment scale ranging from 0 (no psoriasis) to 100 (most severe psoriasis imaginable) were measured.

To verify whether the treatments were equally safe, we assessed the incidence of acute side effects and measured the total cumulative dose of ultraviolet B light. The patients recorded any short term side effects for every irradiation in a diary. We considered four short term side effects of interest: mild erythema and burning sensation (mild and expected side effects) and severe erythema and blistering (serious side effects).

To calculate cumulative doses of ultraviolet B light we routinely measured light intensity $\left(\mathrm{J} / \mathrm{cm}^{2}\right)$ of all equipment from the hospitals with a small portable ultraviolet light meter (585 100; Waldmann, Germany). If the ultraviolet B unit from the hospital had an irradiation intensity indicator, we compared its reading with our own measurements. The home care institutions measured the light intensity of every unit before the first irradiation and after the last irradiation, using their own ultraviolet light meters (all type 585 100; Waldmann). At the end of the trial we collected these measurements and also compared their portable ultraviolet B light meters with our own portable ultraviolet B light meter, which was calibrated using a high accuracy ultraviolet visible spectroradiometer (OL 752; Optronic Laboratories, Orlando, FL). Participants in both groups recorded treatment times in their diary. We also took copies of the treatment charts of the patients treated in hospital. At the end of the trial we calculated standardised cumulative doses 


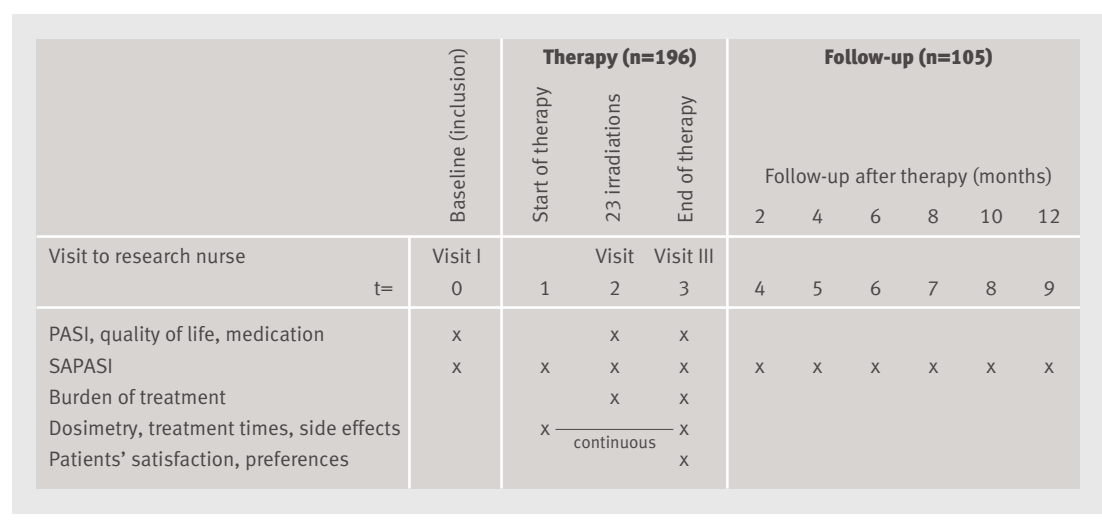

Fig 1 | Schematic representation of planned measurements. PASI=psoriasis area and severity index; SAPASI=self administered psoriasis area and severity index

$\left(\mathrm{mW} / \mathrm{cm}^{2}\right)$ for all patients using the intensity measurements together with the individual treatment charts or diaries, or both. The calculation of standardised cumulative doses is described elsewhere. ${ }^{26}$

To measure the perceived burden of treatment we designed a short four item questionnaire using visual analogue scales ranging from $0-10$ (see web extra). The questionnaire was drawn up to capture the perceived burden of the ultraviolet B treatment, especially the burden of the treatment method and time lost as a result of treatment.

We assessed health related quality of life using a generic and a disease specific questionnaire ${ }^{26}$ : the short form 36 general health survey $(\mathrm{SF}-36)^{3839}$ and the psoriasis disability index. ${ }^{4041}$ The SF-36 questionnaire provides eight domain scores ranging from 0 (lowest imaginable quality of life) to 100 (perfect health). ${ }^{3839}$ The psoriasis disability index has scores ranging from 15 (no disability, highest quality of life) to 105 (lowest quality of life). ${ }^{4041}$ Furthermore, we developed and used a questionnaire on patients' satisfaction and preferences, and collected data on concomitant use of drugs and personal information. ${ }^{26}$ Details on the outcome measures are published elsewhere. ${ }^{26}$

\section{Planning of measurements}

We planned measurements for the 196 participants coinciding with inclusion in the study $(\mathrm{t}=0)$, actual

Table 1| Baseline characteristics of patients with psoriasis allocated to ultraviolet B phototherapy at home or in an outpatient department. Values are means (standard errors of means) unless stated otherwise

\begin{tabular}{|c|c|c|}
\hline Characteristics & Home phototherapy $(n=98)$ & Outpatient phototherapy $(n=98)$ \\
\hline No (\%) of men & $66(67)$ & $66(67)$ \\
\hline Age (years) & $41.2(1.38)$ & $45.0(1.37)$ \\
\hline Duration of psoriasis (years) & $16.1(1.37)$ & $16.0(1.36)$ \\
\hline SAPASI* & $7.2(0.38)$ & $7.3(0.32)$ \\
\hline PASI† & $9.7(0.71)$ & $8.6(0.56)$ \\
\hline $\begin{array}{l}\text { No (\%) with experience of } \\
\text { phototherapy }\end{array}$ & $50(51)$ & $50(51)$ \\
\hline
\end{tabular}

SAPASI=self administered psoriasis area and severity index; PASI=psoriasis area and severity index.

*Score had normal distribution at baseline but showed skewed distribution over course of trial.

†Score had skewed distribution during all measurements. Median values at baseline were 8.4 (home) and 7.1 (outpatient) start of therapy $(\mathrm{t}=1)$, around the 23rd irradiation $(t=2)$, and the end of therapy $(t=3)$. When treatments exceeded 46 irradiations, we defined 46 irradiations as the end of therapy. ${ }^{26}$

To obtain accurate estimates of cumulative costs, some measurements continued every two months for one year after the end of therapy (measurements 4 to 9 ). For this objective only 100 participants were needed; therefore the first consecutive 105 participants were followed for these measurements. Figure 1 schematically represents the planned measurements.

\section{Statistical analysis}

The main principle of our analysis was non-inferiority - that is, we hypothesised that there would be no differences between treatments in clinical outcome, quality of life, and safety. The non-inferiority margin $(\Delta)$ for the primary outcome measures PASI 50 and SAPASI 50 was set at $-15 \%$. Non-inferiority of home ultraviolet B phototherapy was accepted if the lower bound of the two sided 95\% confidence interval around the estimated difference in proportion of patients reaching PASI 50 or SAPASI 50 was above $-15 \%$. We also analysed the secondary outcome measures for non-inferiority, using evaluation of the lower bounds of the $95 \%$ confidence intervals for clinical relevance. The differences at group level are presented with their 95\% confidence intervals.

We used statistical methods in accordance with the type of data to analyse the superiority of patients' satisfaction and burden of treatment. From independent samples we carried out the unpaired $t$ test for normally distributed continuous data. For ordinal data and data with a skewed distribution we used the Mann-Whitney $\mathrm{U}$ test. All analyses were done according to the intention to treat principle.

\section{RESULTS}

Overall, 196 patients were randomised: 98 to home ultraviolet B phototherapy and 98 to outpatient ultraviolet B phototherapy (fig 2). All participants were followed during therapy. The first 105 consecutive patients were also followed for one year after therapy. ${ }^{26}$

Table 1 summarises the baseline characteristics of the 196 patients. The severity of psoriasis at baseline between those patients who completed the study and those who dropped out did not differ. Baseline severity of psoriasis ranged from mild to severe, with individual PASI scores up to 48.6. One hundred patients had had experience of ultraviolet light treatment, eight of whom had experienced home phototherapy. Three of these were allocated to home ultraviolet B phototherapy and five to outpatient ultraviolet B phototherapy.

\section{Treatment effect}

Table 2 shows effectiveness as measured by the SAPASI 50, 75, and 90 and the PASI 50, 75, and 90. Four of these six outcome measures indicated that home ultraviolet B phototherapy was not inferior - that is, was equally effective as (SAPASI 50 and PASI 90), at least equally effective as (SAPASI 75), or even superior to (SAPASI 
90) outpatient ultraviolet B phototherapy for psoriasis. The remaining two measures (PASI 50 and PASI 75) had point estimates suggesting equal effectiveness, but non-inferiority could not be confirmed by the $95 \%$ confidence intervals, of which the lower bounds were slightly lower than $-15 \%$. Supplemental analyses for both measures, however, showed that less than $5 \%$ of the distribution of the $95 \%$ confidence intervals fell below the margin of $-15 \%$.

The treatment effect as defined by the mean decline in SAPASI and PASI scores was statistically significant within (all $\mathrm{P}<0.001)$ and similar $(\mathrm{P}>0.3)$ across both treatment groups.

Table 2 | Main outcome measures for patients with psoriasis randomised to ultraviolet $B$ phototherapy at home or in an outpatient department. Values are percentages (numbers) of patients unless stated otherwise

\begin{tabular}{lccc}
$\begin{array}{l}\text { Variables } \\
\text { Effectiveness }\end{array}$ & $\begin{array}{c}\text { Home } \\
\text { phototherapy }\end{array}$ & $\begin{array}{c}\text { Outpatient } \\
\text { phototherapy }\end{array}$ & $\begin{array}{c}\text { Difference } \\
(95 \% \mathrm{Cl})\end{array}$ \\
\hline SAPASI 50, 75, and 90*: & $(\mathrm{n}=94)$ & $(\mathrm{n}=91)$ & - \\
\hline SAPASI 50 & $81.9(77)$ & $79.1(72)$ & $2.8(-8.6$ to 14.2) \\
\hline SAPASI 75 & $69.1(65)$ & $59.3(54)$ & $9.8(-4.0$ to 23.6) \\
\hline SAPASI 90 & $43.6(41)$ & $29.7(27)$ & $13.9(0.002$ to 27.8) \\
\hline PASI 50, 75, and 90†: & $(\mathrm{n}=91)$ & $(\mathrm{n}=84)$ & - \\
\hline PASI 50 & $70.3(64)$ & $72.6(61)$ & $-2.3(-15.7$ to 11.1) \\
\hline PASI 75 & $40.7(37)$ & $41.7(35)$ & $-1.0(-15.6$ to 13.6) \\
\hline PASI 90 & $19.8(18)$ & $19.0(16)$ & $0.8(-10.9$ to 12.5) \\
\hline
\end{tabular}

\section{Safety}

\begin{tabular}{lccc}
\hline Irradiations: & $(\mathrm{n}=98)$ & $(\mathrm{n}=98)$ & - \\
\hline Mean No of irradiations & 34.4 & 28.6 & $5.8(2.7$ to 9.0$)$ \\
\hline Mean cumulative dose $\left.\mathrm{J} / \mathrm{cm}^{2}\right):$ & $(\mathrm{n}=85)$ & $(\mathrm{n}=68)$ & - \\
\hline At 23 irradiations & 21.2 & 26.9 & $-5.7(-10.3$ to -1.1$)$ \\
\hline & $(\mathrm{n}=91)$ & $(\mathrm{n}=93)$ & \\
\hline At end of therapy & 51.5 & 46.1 & $5.4(-5.2$ to 16.0) \\
\hline Proportion of side effects per & $(\mathrm{n}=93)$ & $(\mathrm{n}=92)$ & -
\end{tabular}

irradiation (\%):

\begin{tabular}{lccc}
\hline Severe erythema & 5.5 & 3.6 & $1.9(-1.1$ to 4.9$)$ \\
\hline Blistering & 0.3 & 0.6 & $-0.3(-0.9$ to 0.3$)$ \\
\hline Burning sensation & 7.1 & 10.0 & $-2.9(-7.1$ to 1.2$)$ \\
\hline Mild erythema & 28.8 & 28.6 & $0.3(-7.4$ to 8.0$)$ \\
\hline Use of adjuvant drugs $\ddagger$ & & & - \\
\hline During waiting time§: & $(\mathrm{n}=94)$ & $(\mathrm{n}=95)$ & $19.2(8.8$ to 29.6$)$ \\
\hline Topical steroids & $25.5(24)$ & $6.3(6)$ & $11.8(2.5$ to 21.1$)$ \\
\hline Vitamin D derivatives & $18.1(17)$ & $6.3(6)$ & \\
\hline During phototherapy: & $(\mathrm{n}=92)$ & $(\mathrm{n}=92)$ & $-20.7(-35.0$ to -6.4$)$ \\
\hline Topical steroids & $31.5(29)$ & $52.2(48)$ & $-20.6(-33.8$ to -7.4$)$ \\
\hline Vitamin D derivatives & $19.6(18)$ & $40.2(37)$ &
\end{tabular}

Waiting time§ and duration of therapy

\begin{tabular}{lccc}
\hline & $(\mathrm{n}=93)$ & $(\mathrm{n}=95)$ & - \\
\hline Mean waiting time§ (weeks) & 5.8 & 2.2 & $3.6(2.9$ to 4.4$)$ \\
\hline Mean duration of therapy (weeks) & 11.4 & 14.1 & $-2.7(-4.1$ to -1.2$)$ \\
\hline Mean time from inclusion to end & 17.2 & 16.2 & $1.0(-0.6$ to 2.5$)$
\end{tabular}

of therapy (weeks)

SAPASI=self administered psoriasis area and severity index; PASI=psoriasis area and severity index. When treatments exceeded 46 irradiations, 46 irradiations is defined as end of therapy. Values shown are calculated from data not exceeding 46 irradiations.

*Proportion of patients achieving at least a $50 \%, 75 \%$, or $90 \%$ decline of baseline SAPASI at end of therapy. tProportion of patients achieving at least a $50 \%, 75 \%$, or $90 \%$ decline of baseline PASI at end of therapy.

†Proportion of patients using adjuvant drugs during two consecutive phases of trial.

§Time between inclusion in trial and starting phototherapy.
Figure 3 illustrates changes in median psoriasis severity (SAPASI) over time. During therapy the median SAPASI score decreased from 6.7 to 1.2 for the home ultraviolet B group and from 7.0 to 1.4 for the outpatient ultraviolet B group; a decline of $82 \%$ and $79 \%$, respectively. Essentially similar results were observed for decline in median PASI scores, from 8.4 to 2.2 for the home ultraviolet $\mathrm{B}$ group compared with 7.0 to 2.1 for the outpatient ultraviolet B group: a decline of $74 \%$ and $70 \%$, respectively. Subgroup analyses for patients with more moderate to severe psoriasis (baseline SAPASI $\geq 10$ ) showed that this subgroup reacted similarly to home ultraviolet B phototherapy as did the average participant. No differences were observed across the treatment groups.

PASI scores measured during the three visits to the research nurse were comparable to the SAPASI scores (data not presented). Correlation coefficients for PASI and SAPASI scores varied between 0.48 and 0.52 $(\mathrm{P}<0.001)$. Mean self assessed scores for psoriasis severity using a visual severity assessment scale (range 0-100) were 70.6 and 70.2 at inclusion and 18.1 and 18.0 at the end of therapy (90 patients in home ultraviolet B group $v 88$ in outpatient ultraviolet B group).

\section{Safety}

To determine whether both treatments were equally safe, the incidence of acute side effects were assessed and the total cumulative dose of ultraviolet B light measured (table 2). Patients treated at home had a higher mean total number of irradiations than patients treated in the outpatient setting. Yet the point estimate of the mean cumulative dose of TL-01 ultraviolet B light at the end of therapy was only slightly higher for patients treated at home (difference $5.4 \mathrm{~J} / \mathrm{cm}^{2}, 95 \%$ confidence interval -5.2 to 16.0$)$.

A total of 6180 irradiations were monitored. Complete information on side effects was available for 6111 irradiations in 185 patients. Regardless of treatment group, $87 \%(\mathrm{n}=161)$ of the patients had at least one occurrence of mild erythema, $58 \%(\mathrm{n}=107)$ a burning sensation, $39 \%(n=73)$ severe erythema, and $6 \%(n=11)$ blistering. No differences were observed between the treatment groups.

Besides the probability of patients experiencing a particular side effect during the entire treatment, also the probability per irradiation was calculated for each patient by dividing the number of side effects during treatment by the number of irradiations. No differences between treatment groups were observed in these outcomes (table 2).

Adjuvant treatment, waiting time, and duration of therapy Adjuvant treatment was divided into topical drugs (for example, vitamin D derivatives, topical corticosteroids, dithranol) and systemic drugs (methotrexate, acitretin, ciclosporin, fumarates). During ultraviolet B treatment, a higher proportion of the patients treated at in the outpatient department used topical steroids and vitamin D derivatives, whereas during waiting 


\section{Patients recruited by participating hospitals $(n=252)$}

\begin{tabular}{|c|c|}
\hline & $\begin{array}{l}\text { Excluded }(n=56) \text { : } \\
\text { Did not meet inclusion criteria }(n=33) \\
\text { Met exclusion criteria }(n=8) \\
\text { Had already started ultraviolet B } \\
\text { phototherapy }(n=2) \\
\text { Excluded for other practical reasons }(n=2) \\
\text { Refused to participate in trial }(n=11)\end{array}$ \\
\hline \multicolumn{2}{|c|}{ Randomised ( $n=196)$} \\
\hline & 7 \\
\hline $\begin{array}{l}\text { Randomised to receive home } \\
\text { ultraviolet B phototherapy }(n=98)\end{array}$ & $\begin{array}{l}\text { Randomised to receive conventional } \\
\text { outpatient ultraviolet B phototherapy }(n=98)\end{array}$ \\
\hline$\downarrow$ & $\downarrow$ \\
\hline $\begin{array}{l}\text { Discontinued intervention }(n=5) \text { : } \\
\text { Switched to outpatient ultraviolet B } \\
\text { phototherapy }(n=1) \\
\text { Did not start ultraviolet B phototherapy }(n=4) \\
\text { (lesions improved in three patients during } \\
\text { waiting time, one did not want treatment } \\
\text { during pregnancy) }\end{array}$ & $\begin{array}{l}\text { Discontinued intervention }(n=7) \text { : } \\
\text { Switched to home ultraviolet B phototherapy } \\
(n=4) \\
\text { Did not start ultraviolet B phototherapy }(n=3) \\
\text { (lesions improved in one patient during } \\
\text { waiting time, one had agoraphobia, one } \\
\text { refused to participate in trial) }\end{array}$ \\
\hline$\downarrow$ & $\downarrow$ \\
\hline $\begin{array}{l}\text { Lost to follow-up ( } n=7) \text { : } \\
\text { (lack of motivation to complete questionnaires } \\
\text { or to visit research nurse, three were patients } \\
\text { who did not start ultraviolet B phototherapy) }\end{array}$ & $\begin{array}{l}\text { Lost to follow-up ( } n=11) \text { : } \\
\text { (lack of motivation to complete questionnaires } \\
\text { or to visit research nurse, two were patients } \\
\text { who did not start ultraviolet B phototherapy) }\end{array}$ \\
\hline$\downarrow$ & $\downarrow$ \\
\hline Completed study $(n=91)$ & Completed study $(\mathrm{n}=87)$ \\
\hline$\downarrow$ & $\downarrow$ \\
\hline Included in analysis $(n=98)$ & Included in analysis $(n=98)$ \\
\hline
\end{tabular}

Fig 2 | Flow of patients through trial $(\mathrm{n}=98)$ at inclusion to 20.9 and $22.0(\mathrm{n}=93$, and $\mathrm{n}=91)$ at the end of therapy. At all three time points of measurement, psoriasis disability index values were similar across groups $(\mathrm{P}>0.45)$. The eight $\mathrm{SF}-36$ domain scores and the two component scores were also similar across the groups. The values were, however, lower than the values observed in an unaffected population sample. ${ }^{39}$

\section{Patients' satisfaction and preferences}

Patients treated at home evaluated their therapy more positively than patients treated in the outpatient department $(\mathrm{P}=0.001)$. For example, treatment was rated as "excellent" by $42 \%(38 / 90)$ of the patients in the home ultraviolet B group compared with 23\% (20/ 88 ) in the outpatient ultraviolet B group (fig 5).

Patients' satisfaction was categorised as satisfaction with the final treatment result (appearance of skin), the rate of improvement, and nursing care and supervision during treatment. Table 3 shows the distribution of the various degrees of satisfaction for the three dimensions.

Waiting time before phototherapy could be started was sometimes considerable. However, $26 \%$ (22/86) of the patients treated at home and $45 \%(26 / 58)$ treated in the outpatient department thought the waiting time was not a problem, and 48\% (41/86) compared with $35 \%(20 / 58)$ thought the waiting time was acceptable. Only a minority thought it was too long $(17 \% v 16 \%)$ or far too long $(9 \% v 5 \% ; \mathrm{P}=0.038)$. Despite the waiting times, most of the participants in both groups said that they would prefer home ultraviolet B phototherapy in the future: $92 \%(83 / 90)$ of patients treated at home compared with $60 \%(53 / 88)$ treated in the outpatient department (difference 32\%, 95\% confidence interval $19.5 \%$ to $44.5 \%$ ). Most of the patients in both groups considered the therapy they received to be very of drug used per patient was similar for both treatme groups. During waiting time and therapy, use of other topical and systemic drugs was negligible and did not differ across treatment groups.

Waiting time was longer for patients treated at home than for patients treated in the outpatient department (fig 3 and table 2). This did not result in a clinically relevant difference in total duration until the end of treatment.

\section{Burden of treatment}

The burden of treatment was measured after 23 irradiations and at the end of therapy. Results for both time points were virtually identical; therefore the overall average values are presented. The burden of treatment was significantly higher for patients treated in the outpatient department than for those treated at home. Differences in mean scores for the four domains were 1.23 to 3.01 ( $\mathrm{P} \leq 0.001$ for all; fig 4$)$.

\section{Quality of life}

Both disease specific quality of life (psoriasis disability index) and generic quality of life (SF-36) improved during therapy. The psoriasis disability index values decreased from 32.8 in the home ultraviolet B group $(n=98)$ and 34.3 in the outpatient ultraviolet B group

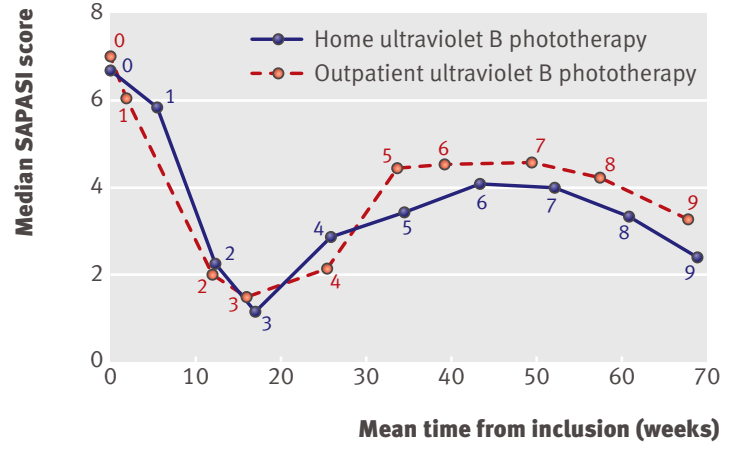

Fig 3 Median self administered psoriasis area and severity index (SAPASI) scores against time. 0 =baseline (98 home patients $v 98$ outpatients); 1=start of therapy (93 $v$ 94), 2=23 irradiations ( $90 \vee 74$ ), $3=$ end of therapy (when ultraviolet $B$ treatment exceeded 46 irradiations, the 46th irradiation was defined as end of therapy; $94 v$ 91), 4=2 months after therapy (51 v 43), 5=4 months after therapy ( $52 v 44), 6=6$ months after therapy ( $50 v 44), 7=8$ months after therapy (50 $v 43), 8=$ 10 months after therapy ( $49 v 42), 9=12$ months after therapy (47 v 40). From measurement 0-3 all 196 participants were followed. From measurement 4-9 only a consecutive sample of 105 participants was followed 
safe (32\% home ultraviolet B group $v 21 \%$ outpatient ultraviolet B group) or safe (52\% v 63\%). About 16\% (29/178) reported being impartial, and none of the participants thought the therapy they received was unsafe $(\mathrm{P}=0.156)$.

\section{DISCUSSION}

In contrast to prevailing opinion, ${ }^{12-25}$ ultraviolet B phototherapy used at home is equally effective for treating psoriasis as ultraviolet B phototherapy administered in an outpatient setting and implies no additional safety hazards if applied in a setting precluding possible non-prescribed irradiations. Furthermore, ultraviolet B phototherapy at home poses a lower burden, is better appreciated, and gives similar improvements in quality of life. Most of the patients said that they would prefer home ultraviolet B phototherapy over therapy in an outpatient setting for future treatment.

Four of six measures of the SAPASI 50, 75, and 90 and PASI 50, 75, and 90 indicated that home ultraviolet $\mathrm{B}$ phototherapy for psoriasis is at least equally effective as, or even superior to, ultraviolet B phototherapy in an outpatient department. The remaining two measures had point estimates suggesting equal effectiveness, but from the $95 \%$ confidence intervals possible inferiority of home ultraviolet B phototherapy could not be entirely excluded. Also, the similar decrease in the PASI as well as SAPASI scores and the visual severity assessment score adds to the conclusion of similar effectiveness. The proportion of patients reaching the SAPASI 90 shows that home ultraviolet B phototherapy may be more effective than such treatment in the

\begin{tabular}{|c|c|c|c|}
\hline Dimensions and items & Home phototherapy & Outpatient phototherapy & $\mathrm{P}$ value $\dagger$ \\
\hline Final treatment resultł: & $(n=90)$ & $(n=88)$ & \\
\hline Very satisfied & $49(44)$ & $32(28)$ & \multirow{5}{*}{0.08} \\
\hline Satisfied & $32(29)$ & $47(41)$ & \\
\hline Somewhat satisfied & $11(10)$ & $18(16)$ & \\
\hline Unsatisfied & $7(6)$ & $3(3)$ & \\
\hline Very unsatisfied & $1(1)$ & $0(0)$ & \\
\hline Rate of improvement: & $(n=90)$ & $(n=88)$ & \\
\hline Very satisfied & $36(32)$ & $27(24)$ & \multirow{5}{*}{0.34} \\
\hline Satisfied & $40(36)$ & $44(39)$ & \\
\hline Somewhat satisfied & $18(16)$ & $25(22)$ & \\
\hline Unsatisfied & $4(4)$ & $2(2)$ & \\
\hline Very unsatisfied & $2(2)$ & $1(1)$ & \\
\hline Nursing care and supervision: & $(n=87)$ & $(n=85)$ & \\
\hline Very satisfied & $35(30)$ & $51(43)$ & \multirow{5}{*}{0.02} \\
\hline Satisfied & $49(43)$ & $41(35)$ & \\
\hline Somewhat satisfied & $13(11)$ & $7(6)$ & \\
\hline Unsatisfied & $3(3)$ & $1(1)$ & \\
\hline Very unsatisfied & $0(0)$ & $0(0)$ & \\
\hline
\end{tabular}

*Prevalence of various degrees of satisfaction (very satisfied to very unsatisfied).

†Mann-Whitney U test.

$\ddagger$ Appearance of psoriasis.

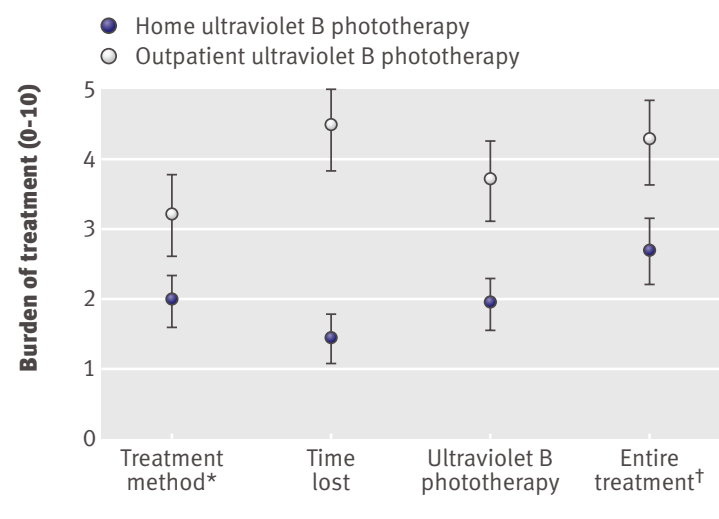

Aspects of treatment

Fig 4 | Mean burden of treatment values on a 0-10 visual analogue scale for 92 patients randomised to receive ultraviolet B phototherapy at home and 89 to receive ultraviolet B phototherapy in an outpatient setting. Error bars are $95 \%$ confidence intervals. *For example, location of treatment (home $v$ hospital), positioning for irradiation, actions for patient to perform. †Includes use of creams and ointments or taking drugs for psoriasis ( 87 home patients $v$ 83 outpatients)

outpatient department. This was not, however, confirmed by the PASI 90 score. Possibly the patients' responses may have been biased, resulting in optimistic assessment on near complete recovery.

Interestingly, in both groups the severity of the psoriasis had already improved during the waiting period, before ultraviolet B phototherapy was started. This early improvement might result from patients being empowered and increasing their compliance with topical drugs after the recent visit to the dermatologist. The knowledge that ultraviolet B phototherapy would soon be started might also have reduced possible stress factors influencing the severity of psoriasis and its perception. Finally, the improvement may also be partly explained by regression to the mean. ${ }^{42}$

Besides being equally effective, both treatments were equally safe, as judged by the similar proportion of acute side effects experienced and the safety of the treatment as perceived by the patients. Therefore our results refute the widespread fear of more acute safety risks with ultraviolet $B$ phototherapy used at home. ${ }^{12151619-2125}$

The same conclusion can be drawn about the fear of higher cumulative doses and long term safety such as carcinogenicity and photoageing. In our trial the final cumulative dose of ultraviolet B light was not significantly different between the treatment groups. As the attributive long term risk for skin cancer caused by ultraviolet B phototherapy is believed to correlate directly with the experience of acute side effects and with the total cumulative dose of ultraviolet B light, ${ }^{43-45}$ we conclude that the risk of future skin cancer attributable to treatment would also be similar across the groups. Another argument is that a possible difference of $5.4 \mathrm{~J} / \mathrm{cm}^{2}$ in total cumulative dose $(95 \%$ confidence interval -5.2 to 16.0 ) corresponds to a difference 


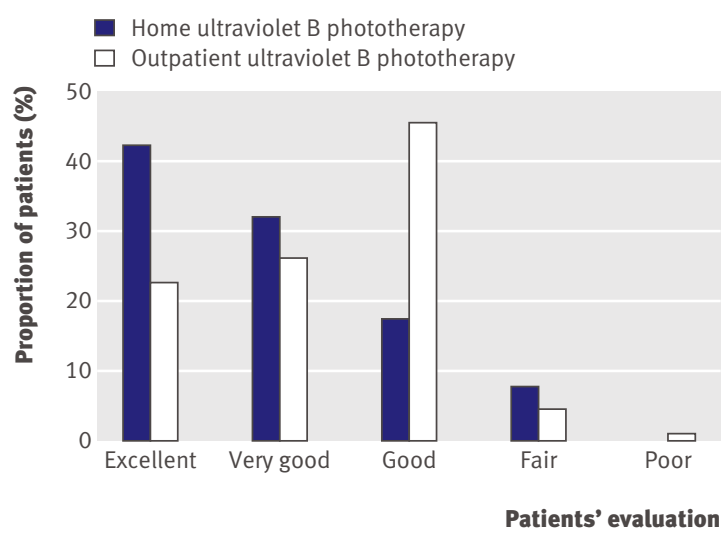

Fig 5 | Patients' self rated global experience of ultraviolet B phototherapy

of about 9 minimal erythema doses (95\% confidence interval values correspond to -9 and 26 ). This was calculated using the action spectrum from Parrish, ${ }^{46}$ the TL-01 emission spectrum, ${ }^{47}$ and an average erythemal effective dose for skin types 2 and 3 of $35 \mathrm{~mJ} / \mathrm{cm}^{2}{ }^{4849}$ In the Netherlands the mean solar exposure is 75 minimal erythema doses annually for indoor workers and 170 minimal erythema doses annually for outdoor workers. ${ }^{50}$ Therefore a mean difference of 9 minimal erythema doses per year in our opinion seems insignificant and certainly not sufficient to favour outpatient ultraviolet B phototherapy over home treatment. Even the extreme of the confidence intervals (26 minimal erythema doses) is in our opinion still not sufficient or relevant to favour one therapy over another.

Concerns about unsupervised continuation or restart of irradiations at home is not an issue in the Netherlands. Home ultraviolet B phototherapy units are rented out by home care institutions only when prescribed by a dermatologist and are collected at the end of treatment. Therefore in this setting multiple annual ultraviolet $B$ treatments are only possible if prescribed. We are aware that this situation may not apply to other countries, such as in those where patients buy their own unit. On the basis of this trial we cannot make any statements on the risk of non-prescribed irradiations in such settings. Recently, however, one study ${ }^{51}$ described another measure that also provides additional safety through preventing long term use and misuse. The study used home ultraviolet $B$ light panels that were fitted with an electronic control to allow a preset number of irradiations. When this number had been used the patients had to contact their dermatologist for a new code to obtain additional irradiations. ${ }^{51}$ Other ways to prevent non-prescribed use of home ultraviolet B light therefore exist and are being used.

Because of the pragmatic design of our study the use of concomitant drugs was permitted throughout the trial. We observed a higher proportion of the patients treated at home using topical steroids or vitamin D derivatives while awaiting phototherapy. We think this difference is attributable to the long waiting time for home ultraviolet phototherapy, which was almost three times as long as the average wait for treatment in the outpatient clinic. That during ultraviolet B treatment a higher proportion of patients treated in hospital used these two types of drugs might be explained by closer supervision and more nursing care, resulting in more motivation to use adjuvant drugs. Differential use of drugs during waiting time and during ultraviolet therapy, however, had no effect on overall outcome.

The considerable waiting time before home treatment resulted from the national health insurance system and capacity problems at the home care institutions during winter. Duration of home ultraviolet B phototherapy was, however, shorter than outpatient treatment, supposedly due to the difference in irradiation frequency and the resulting difference in rate of improvement. ${ }^{5253}$ Thus, despite the longer waiting time for home ultraviolet B treatment, the mean time from inclusion up to the end of the treatment (waiting time plus treatment duration) was similar for both groups.

Our findings indicate that ultraviolet B phototherapy at home results in a lower burden of treatment than ultraviolet B phototherapy in the outpatient department. The results of the burden of treatment questionnaire showed more comfort and a lower burden for patients treated at home. Improvement in quality of life, however, was similar for both groups. This was because the quality of life questionnaires were not therapy specific, but disease specific (psoriasis disability index) or even generic (SF-36). Disease severity decreased similarly in both groups, hence it might be expected that general or disease specific quality of life would improve similarly in the groups. An official therapy specific quality of life questionnaire does not exist however. We believe that the questionnaire we developed was suitable to report burden of treatment and can be considered a good predictor of therapy specific quality of life.

Patients treated in the outpatient setting were in general slightly more satisfied with the nursing care and supervision. However, the longer waiting time for home ultraviolet B treatment was not an issue for most patients. In fact most participants in both groups would prefer home ultraviolet $B$ treatment over hospital based ultraviolet B treatment in the future. This finding was more explicit for patients treated at home $(92 \%)$ than for those treated in outpatient departments (60\%). This difference probably results from a difference in experience with home ultraviolet B treatment, as this item was recorded after the treatment had finished. In our opinion most patients found home ultraviolet $\mathrm{B}$ phototherapy comfortable, flexible, and less time consuming than hospital based treatment. This led to higher reported satisfaction with home phototherapy than with outpatient phototherapy. Patients therefore apparently prefer a comfortable treatment regimen over a rapid start of treatment. This would also explain why home ultraviolet B treatment was better appreciated by the patients. 


\section{Comparison with other studies}

As our study is the first randomised controlled trial of ultraviolet B phototherapy at home, we have little with which to compare our results. We found only two observational parallel group studies. ${ }^{11925}$ In both, home ultraviolet B phototherapy seemed to be effective. No information about severity of psoriasis at baseline was provided, however, and neither study had a randomised design. ${ }^{11}{ }^{19}$ Patients in our trial had, as judged by the baseline PASI and SAPASI scores, a severity of disease ranging from mild to severe. The average severity of psoriasis was comparable to that of a non-selected group of 23 patients receiving ultraviolet B phototherapy in our hospital from August 2006 to July 2007 (median SAPASI 7.55). The mean baseline PASI and SAPASI scores in our trial were also similar to those of a trial where participants were said to be representative of patients receiving ultraviolet $\mathrm{B}$ phototherapy ${ }^{54}$ but were somewhat higher than those in a study where the same principal inclusion criterion of clinical eligibility had been used. ${ }^{55}$

Effectiveness in terms of percentage decline in baseline PASI and SAPASI score was similar to that of three other trials studying the effect of narrowband ultraviolet B light. ${ }^{56-58}$ Effectiveness was also comparable to that of ciclosporin and etanercept but somewhat higher than that of methotrexate and efalizumab and lower than that of infliximab and adalimumab..$^{59-65}$ Overall we think our results may be considered representative and can be extrapolated to many other settings.

When it comes to safety of home ultraviolet B treatment, four of six published guidelines on home ultraviolet $\mathrm{B}$ phototherapy for psoriasis presume that such treatment leads to inaccurate dosimetry, suboptimal treatment, phototoxicity, and higher attendant risks. ${ }^{1620-2225}$ Also, three guidelines claim that medical supervision is crucial for treatment effect. ${ }^{1620225}$ Accordingly, most papers and guidelines on home ultraviolet $B$ phototherapy suggest caution when prescribing this treatment and advise using strict eligibility criteria to select patients. ${ }^{811} 1215161820222566$ In our study we showed that home ultraviolet B treatment was equally effective and equally safe as ultraviolet $B$ treatment in the outpatient department, and that eligibility criteria for home ultraviolet $\mathrm{B}$ phototherapy can be broad. To provide an effective and safe treatment at home, we believe that there is no need to select patients based on their presumed higher intelligence, competence, responsibility, reliability, or compliance. ${ }^{111215161820222566}$

\section{Strengths and weaknesses of the study}

A major strength of this study is that it is the first randomised trial on the effectiveness, quality of life, and burden of treatment of home ultraviolet B phototherapy for psoriasis compared with standard ultraviolet B phototherapy in an outpatient setting. ${ }^{25}$ These issues have never before been properly investigated nor published.

We used a pragmatic design to be able to compare the two treatments under conditions in which they would be applied in daily practice. The design ensured broad inclusion of patients who were clinically eligible for ultraviolet B phototherapy. We believe that our participants adequately represent patients with psoriasis receiving ultraviolet $B$ phototherapy outside the trial. Additionally, that treatments were similar to daily practice ensured that our results may be generalised to the target population. However, we recognise that in a setting lacking control and good maintenance of the home ultraviolet B light units, the results of the treatment might be different.

A potential weakness may be the manner in which data collection was planned. This was organised such that both treatment groups could be compared without important differences in the number of irradiations. However, this aspect of the design made it impossible to compare the groups at fixed times-for example, at four or eight weeks after the start of treatment. Another point of consideration might be that during the trial 252 patients were referred to us, of whom 196 consented to participate in the trial. We know why the 56 (252-196) patients were excluded. ${ }^{26}$ It was not possible, however, to keep a record of all patients with psoriasis who were prescribed narrowband ultraviolet B phototherapy but were not referred to us for inclusion in the trial. We therefore do not know the reasons for non-referral and cannot entirely exclude selection bias. Such bias would, however, be minimal as the included patients matched a consecutive sample of patients offered ultraviolet B phototherapy in our hospital at a later period.

\section{Implications for practice}

Our study provides proper evidence for dermatologists and dermatological societies, allowing definitive statements about effectiveness, safety, quality of life, and burden of treatment of ultraviolet B phototherapy at home. Since the effectiveness of home and hospital treatments was equal, future decisions should be based on the burden of treatment, patient satisfaction, and the economic burden for society. Now that we have provided the evidence and discussed the merits of home ultraviolet B treatment, we think that a considered policy decision and subsequent adaptation of guidelines would be possible.

\section{Conclusions}

We have shown that ultraviolet B phototherapy at home is equally effective and equally safe as ultraviolet B phototherapy in an outpatient department when applied in a setting that precludes non-prescribed irradiations. Treatment at home also led to a lower burden of treatment and greater patients' satisfaction than did ultraviolet B phototherapy in an outpatient setting, despite waiting times sometimes being considerably longer. We therefore regard home ultraviolet B phototherapy to be a worthy alternative to standard outpatient ultraviolet B phototherapy for patients with psoriasis. An economic evaluation comparing both treatments should follow to determine which treatment is economically preferred. 


\section{WHAT IS ALREADY KNOWN ON THIS TOPIC}

Two observational studies indicated that ultraviolet B phototherapy at home might be equally effective as ultraviolet $B$ phototherapy in an outpatient setting

Randomised evidence and evidence based guidelines on home ultraviolet B phototherapy are lacking, and general consensus suggests being prudent

Half of dermatologists think home ultraviolet B phototherapy is inferior to outpatient treatment, and almost a third think it carries higher risks

\section{WHAT THIS STUDY ADDS}

Randomised evidence shows that ultraviolet B phototherapy at home is at least equally effective as and equally safe as treatment in an outpatient setting

Home treatment was associated with a lower burden of treatment and greater patients' satisfaction

Home ultraviolet B phototherapy provides a good alternative to outpatient ultraviolet B treatment
8 Jordan WP Jr, Clarke AM, Hale RK. Long-term modified Goeckerman regimen for psoriasis using an ultraviolet $B$ light source in the home. Am Acad Dermatol 1981;4:584-91.

9 Van Vloten WA. [Home treatment of psoriasis using ultraviolet-B irradiation]. Ned Tijdschr Geneeskd 1993;137:2525-6.

10 Matto DM, van den Berg-Tap RMC. [Phototherapy at home. More privacy for patients with psoriasis]. Medisch Contact 2003;58(23):950-2.

11 Cameron H, Yule S, Moseley H, Dawe RS, Ferguson J. Taking treatment to the patient: development of a home TL-01 ultraviolet B phototherapy service. Br J Dermatol 2002;147:957-65.

12 Lowe NJ. Home ultraviolet phototherapy. Semin Dermatol 1992;11:284-6.

13 Feldman SR, Clark A, Reboussin DM, Fleischer AB Jr. An assessment of potential problems of home phototherapy treatment of psoriasis. Cutis 1996;58:71-3.

14 Physicians change attitude about home UVB treatment. Natl Psoriasis Found Bull 1991;22:15.

15 Gerritsen MJP. [Home treatment of psoriasis using ultraviolet B irradiation]. Ned Tijdschr Dermatol Venereol 2000;10:101-2.

16 Sarkany RPE, Anstey A, Diffey BL, Jobling R, Langmack K, McGregor JM, et al. Home phototherapy: report on a workshop of the British Photodermatology Group, December 1996. Br I Dermatol 1999;140:195-9.

17 Prince A, van Leussen J. [Home treatment of psoriasis using ultraviolet B irradiation]. Ned Tijdschr Geneeskd 1994;138:373-4.

We thank the patients; Chantal Cornelis (research nurse) for coordinating the contacts with the patients and with the participating hospitals and home care institutions; the dermatologists, residents, and other contributing employees of the Departments of Dermatology of the following hospitals: University Medical Center Utrecht, Hilversum Hospital, Academic Hospital Maastricht, Diakonessen Hospital Utrecht and Zeist, Meander Hospital Amersfoort, Groene Hart Hospital Gouda, Academic Medical Center Amsterdam, Erasmus Medical Center Rotterdam, Vrije Universiteit Medical Center Amsterdam, Gelre Hospital Apeldoorn, Reinier de Graaf Groep Delft and Voorburg

AntoniusMesosGroup Hospitals Utrecht, and the Lucas Andreas Hospital Amsterdam; and all employees of the participating home care institutions Medizorg, Farmadomo, and stichting Begeleiding Extramurale zorg (BEM)

Contributors: MBGK, EB, PHAS, VS, and CAFMB-K contributed to the study concept and design. MBGK, HvW, and Chantal Cornelis were involved in the acquisition of data, and HvW and Chantal Cornelis provided administrative, technical, and material support. MBGK, EB and VS played a part in the analysis and interpretation of the data. MBGK was the overall study manager and drafted the manuscript. All authors revised the manuscript critically for important intellectual content and gave final approval of the manuscript to be submitted for publication. VS is the guarantor.

Funding: This study was supported by grant 945-02-017 from the Netherlands Organisation for Health Research and Development. The funder had no role in the study design; in the collection, management, analysis, and interpretation of data; in the preparation, review, or approval of the manuscript, or in the decision to submit the article for publication. The researchers are independent from the funders.

Competing interests: None declared.

Ethical approval: This study was approved by the institutional review board of the University Medical Center Utrecht (02/090-0).

1 Anon. An appraisal of narrowband (TL-01) UVB phototherapy. British Photodermatology Group workshop report (Apr 1996). Br J Dermatol 1997;137:327-30.

2 Ibbotson SH, Bilsland D, Cox NH, Dawe RS, Diffey B, Edwards C, et al. An update and guidance on narrowband ultraviolet $B$ phototherapy: a British Photodermatology Group workshop report. Br J Dermatol 2004;151:283-97.

3 Naldi L, Griffiths CE. Traditional therapies in the management of moderate to severe chronic plaque psoriasis: an assessment of the benefits and risks. Br / Dermatol 2005:152:597-615.

4 Barbagallo J, Spann CT, Tutrone WD, Weinberg JM. Narrowband UVB phototherapy for the treatment of psoriasis: a review and update. Cutis 2001;68:345-7.

5 Milstein HJ, Vonderheid EC, Van Scott EJ, Johnson WC. Home ultraviolet phototherapy of early mycosis fungoides: preliminary observations. J Am Acad Dermatol 1982;6:355-62.

6 Resnik KS, Vonderheid EC. Home UV phototherapy of early mycosis fungoides: long-term follow-up observations in thirty-one patients. $J$ Am Acad Dermatol 1993;29:73-7.

7 Larko O, Swanbeck G. Home solarium treatment of psoriasis. Br J Dermatol 1979;101:13-6.
18 Abel EA. Considerations in the use of home ultraviolet radiation therapy for psoriasis. Cutis 1985;35:127-8, 130.

19 Paul BS, Stern RS, Parrish JA, Arndt KA. Low-intensity selective UV phototherapy. A clinical trial in outpatient therapy for psoriasis. Arch Dermatol 1983;119:122-4.

20 Task Force on Psoriasis of the Netherlands Society for Dermatology and Venereology. [Guideline: Photo(chemo)therapy and systemic therapy in severe chronic plaque type psoriasis]. 2008. www.cbo.nl/ product/richtlijnen/folder20021023121843/rl_psoriasis_2005. pdf?

21 Murphy GM, McCann P, O'Leary A, Rogers S. Guidelines for the use of phototherapy and photochemotherapy in Ireland. Ir J Med Sci 1997;166:92-7.

22 Committee on Guidelines of Care, Task Force on Phototherapy and Photochemotherapy. Guidelines of care for phototherapy and photochemotherapy. J Am Acad Dermatol 1994;31:643-8.

23 Committee on Guidelines of Care, Task Force on Psoriasis. Guidelines of care for psoriasis. J Am Acad Dermatol 1993;28:632-7.

24 Biella U, Heller G, Barth J, Borissenko KK, Korotkij NG, Horkay I, et al. [Survey on current status of home treatment of psoriasis patients with ultraviolet irradiation equipment]. Z Arztl Fortbild (Jena) 1985;79(12):531-3.

25 Koek MBG, Buskens E, Bruijnzeel-Koomen CAFM, Sigurdsson V. Home ultraviolet B phototherapy for psoriasis: discrepancy between literature, guidelines, general opinions and actual use. Results of a literature review, a web search, and a questionnaire among dermatologists. Br J Dermatol 2006;154:701-11.

26 Koek MBG, Buskens E, Steegmans PHA, van Weelden H, BruijnzeelKoomen CAFM, Sigurdsson V. UVB phototherapy in an outpatient setting or at home: a pragmatic randomised single-blind trial designed to settle the discussion. The PLUTO study. BMC Med Res Methodol 2006;6:39.

27 Schwartz D, Lellouch J. Explanatory and pragmatic attitudes in therapeutical trials. / Chron Dis 1967;20:637-48.

28 Roland M, Torgerson DJ. What are pragmatic trials? BMJ 1998;316:285.

29 Pragmatic versus explanatory trials. 2008. www.collemergencymed. ac.uk/CEM/Research/technical_guide/pragex.htm.

30 Soares I, Carneiro AV. Intention-to-treat analysis in clinical trials: principles and practical importance. Rev Port Cardiol 2002:21:1191-8.

31 Pocock SJ. The size of a clinical trial. Clinical trials. A practical approach. Chichester: Wiley, 1993:123-41.

32 Spuls PI, Witkamp L, Bossuyt PM, Bos JD. A systematic review of five systemic treatments for severe psoriasis. Br J Dermatol 1997;137:943-9.

33 Pocock SJ. Methods of randomization. Clinical trials. A practical approach. Chichester: Wiley, 1993:66-89.

34 Fredriksson T, Pettersson U. Severe psoriasis-oral therapy with a new retinoid. Dermatologica 1978;157:238-44.

35 Feldman SR, Fleischer AB Jr, Reboussin DM, Rapp SR, Exum ML, Clark AR, et al. The self-administered psoriasis area and severity

36 Fleischer AB Jr, Rapp SR, Reboussin DM, Vanarthos JC, Feldman SR. Patient measurement of psoriasis disease severity with a structured instrument. J Invest Dermatol 1994;102:967-9.

37 Fleischer AB Jr, Feldman SR, Dekle CL. The SAPASI is valid and responsive to psoriasis disease severity changes in a multi-cente clinical trial. J Dermatol 1999;26:210-5. index is valid and reliable. J Invest Dermatol 1996;106:183-6. 
38 Ware JE Jr, Sherbourne CD. The MOS 36-item short-form health survey (SF-36). I: conceptual framework and item selection. Med Care 1992;30:473-83.

39 Aaronson NK, Muller M, Cohen PD, Essink-Bot ML, Fekkes M, Sanderman R, et al. Translation, validation, and norming of the Dutch language version of the SF-36 health survey in community and chronic disease populations. J Clin Epidemiol 1998;51:1055-68.

40 Finlay AY, Kelly SE. Psoriasis-an index of disability. Clin Exp Dermatol 1987;12:8-11.

41 Finlay AY, Khan GK, Luscombe DK, Salek MS. Validation of sickness impact profile and psoriasis disability index in psoriasis. $\mathrm{Br}$ J Dermatol 1990;123:751-6.

42 Trochim WMK. Regression to the mean. In: The research methods knowledge base, 2nd edn. 2006. www.socialresearchmethods.net/kb/regrmean.php.

43 De Gruijl FR, van Kranen HJ, Mullenders LH. UV-induced DNA damage, repair, mutations and oncogenic pathways in skin cancer. J Photochem Photobiol B 2001;63(1-3):19-27.

44 Kricker A, Armstrong BK, English DR, Heenan PJ. Does intermittent sun exposure cause basal cell carcinoma? A case-control study in Western Australia. Int J Cancer 1995;60:489-94.

45 Holman CD, Armstrong BK. Cutaneous malignant melanoma and indicators of total accumulated exposure to the sun: an analysis separating histogenetic types. J Natl Cancer Inst 1984;73:75-82.

46 Parrish JA, Jaenicke KF, Anderson RR. Erythema and melanogenesis action spectra of normal human skin. Photochem Photobiol 1982;36:187-91.

47 Van Weelden H, De La Faille HB, Young E, van der Leun JC. A new development in UVB phototherapy of psoriasis. $\mathrm{Br} J$ Dermatol 1988;119:11-9.

48 Snellman E, Jansen CT, Leszczynski K, Visuri R, Milan T, Jokela K. Ultraviolet erythema sensitivity in anamnestic (I-IV) and phototested (1-4) Caucasian skin phototypes: the need for a new classification system. Photochem Photobiol 1995;62:769-72.

49 Fitzpatrick TB. The validity and practicality of sun-reactive skin types I through VI. Arch Dermatol 1988;124:869-71.

50 Slaper H, Schothorst AA, van der Leun JC. Risk evaluation of UVB therapy for psoriasis: comparison of calculated risk for UVB therapy and observed risk in PUVA-treated patients. Photodermatol 1986;3:271-83.

51 Yelverton CB, Yentzer BA, Clark A, Pearce DJ, Balkrishnan R, Camacho FT, et al. Home narrowband UV-B phototherapy in combination with low-dose acitretin in patients with moderate to severe psoriasis. Arch Dermatol 2008;144:1224-5.

52 Cameron H, Dawe RS, Yule S, Murphy J, Ibbotson SH, Ferguson J. A randomized, observer-blinded trial of twice vs three times weekly narrowband ultraviolet $B$ phototherapy for chronic plaque psoriasis. Br J Dermatol 2002;147:973-8.

53 Dawe RS, Wainwright NJ, Cameron H, Ferguson J. Narrow-band (TL01) ultraviolet B phototherapy for chronic plaque psoriasis: three times or five times weekly treatment? Br J Dermatol 1998;138:833-9.
54 Kirke SM, Lowder S, Lloyd JJ, Diffey BL, Matthews JN, Farr PM. A randomized comparison of selective broadband UVB and narrowband UVB in the treatment of psoriasis. J Invest Dermatol 2007;127:1641-6.

55 Gupta G, Long J, Tillman DM. The efficacy of narrowband ultraviolet B phototherapy in psoriasis using objective and subjective outcome measures. Br J Dermatol 1999;140:887-90.

56 Tanew A, Radakovic-Fijan S, Schemper M, Honigsmann H. Narrowband UV-B phototherapy vs photochemotherapy in the treatment of chronic plaque-type psoriasis: a paired comparison study. Arch Dermatol 1999;135:519-24.

57 Leaute-Labreze C, Saillour F, Chene G, Cazenave C, Luxey-Bellocq ML, Sanciaume C, et al. Saline spa water or combined water and UV-B for psoriasis vs conventional UV-B: lessons from the Salies de Bearn randomized study. Arch Dermato 2001;137:1035-9.

58 Carrozza P, Hausermann P, Nestle FO, Burg G, Boni R. Clinical efficacy of narrow-band UVB $(311 \mathrm{~nm})$ combined with dithranol in psoriasis. An open pilot study. Dermatology 2000;200:35-9.

59 Heydendael VMR, Spuls PI, Opmeer BC, de Borgie CAJM, Reitsma JB, Goldschmidt WFM, et al. Methotrexate versus cyclosporine in moderate-to-severe chronic plaque psoriasis. $N$ Engl J Med 2003;349:658-65.

60 Flytstrom I, Stenberg B, Svensson A, Bergbrant IM. Methotrexate vs ciclosporin in psoriasis: effectiveness, quality of life and safety. A randomized controlled trial. Br J Dermatol 2008;158:116-21.

61 Leonardi CL, Powers JL, Matheson RT, Goffe BS, Zitnik R, Wang A, et al. Etanercept as monotherapy in patients with psoriasis. $N$ Engl J Med 2003;349:2014-22.

62 Lebwohl M, Tyring SK, Hamilton TK, Toth D, Glazer S, Tawfik NH, et al. A novel targeted T-cell modulator, efalizumab, for plaque psoriasis. $N$ Engl J Med 2003;349:2004-13.

63 Gottlieb AB, Evans R, Li S, Dooley LT, Guzzo CA, Baker D, et al. Infliximab induction therapy for patients with severe plaque-type psoriasis: a randomized, double-blind, placebo-controlled trial. J Am Acad Dermatol 2004;51:534-42.

64 Saurat JH, Stingl G, Dubertret L, Papp K, Langley RG, Ortonne JP, et al. Efficacy and safety results from the randomized controlled comparative study of adalimumab vs methotrexate vs placebo in patients with psoriasis (CHAMPION). Br J Dermatol 2007;158:558-66.

65 Papoutsaki M, Chimenti MS, Costanzo A, Talamonti M, Zangrilli A, Giunta A, et al. Adalimumab for severe psoriasis and psoriatic arthritis: an open-label study in 30 patients previously treated with other biologics. J Am Acad Dermatol 2007; 57:269-75.

66 German Dermatological Society (DDG) Professional Association of German Dermatologists (BVDD), German Psoriasis Foundation (DPB). [Consensus letter home UV treatment for psoriasis]. 18 Feb, 1999.

Accepted: 29 December 2008 